is the RNA primer removed from the RNA template to allow transcription of the anti-primer region?

None of these unsolved problems has affected the great usefulness of the viral reverse transcriptase in identifying the presence or involvement of RNA tumour viruses-particularly in human neoplasias. One still hopes for a specific inhibitor in order to test its effect on tumour growth-inhibition of reverse transcription is the only known virus-specific step which would not affect normal cellular functions. Here H. Temin might object: he believes a reverse transcriptase plays a part not only in viral replication but also in normal cell development, for example in gene amplification. So far there is only weak evidence in favour of this exciting idea-but Temin was right once before!

\section{Androgens converted to oestrogens}

\author{
from our Steroid Biochemistry \\ Correspondent
}

Almost 20 years ago it was demonstrated that androgenic steroids could be converted to oestrogenic ones even in the absence of steroid-producing endocrine organs: administration of testosterone to adrenalectomised ovariectomised women increased the urinary excretion of oestrogens. Recent studies have been concerned with the sites where such an aromatisation may occur and with the possibility that even a low level of conversion has an important effect at those sites.

Most tissues, including liver, seem able to bring about this conversion. Breast fat can form oestrogens (Nimrod and Ryan, J. clin. Endocr., 10, $367-372 ; 1975)$ and both abdominal and axillary fat can convert androstenedione to oestrone. This conversion by adipose tissue is surprising as one might expect the lipophilic steroid to be protected from the active enzymes by dissolving in the fat. Even though the rate at which oestrogens are produced in vitro by adipose tissue is very low, the large proportion of adipose tissue in the body (up to $30 \%$ ) may make this tissue an important source. Oestrogens may have an important role in the aetiology and treatment of breast cancer; a large proportion of tumours are known to be oestrogen dependent and contain oestrogen receptors. But fat from normal breast tissue and that from subjects with cancer seems to have identical aromatising ability. Although oestrone is the main product formed, small amounts of oestradiol are also obtained.

Oestrogens may have a role in hair growth and the presence of the aromatising enzyme system in anagen hair roots has also been demonstrated recently in vitro (Schweikert, Milewich and Wilson, J. clin. Endocr., 40, 413417 ; 1975).

Diencephalic tissue from human foetuses (Naftolin, Ryan and Petro, J. clin. Endocr., 33, 368-370; 1971) or limbic areas of rat brain (Lieberburg and McEwen, Brain Res., 85, 165-170; 1975) are able to aromatise testosterone or androstenedione but such conversion is negligible when cerebral cortical tissue is used. Whereas the radioactivity associated with oestradiol accounted for less than $1 \%$ of the radioactivity in the whole homogenate of the limbic areas of rat brain, in the nuclei oestradiol radioactivity counted for almost half the total. Although oestradiol could have been formed peripherally and taken up by the brain, the evidence would seem to show that oestrogens can be produced from C-19 steroids such as testosterone and androstendione.

Marked changes in reproductive function can be caused by the administration of either testosterone or oestrogens to neonatal rats. This and other evidence suggests that the conversion of androgens to oestrogens in certain areas of the brain may have important effects on brain differentiation, sexual behaviour and the production of pituitary hormones.

\section{Dilatancy and aftershocks}

\section{from Peter J. Smith}

Dilatancy models are generally thought of in connection with either earthquake precursors or man-made earthquakes such as those induced by fluid injection at Denver, Colorado, during the mid-1960s. And though not everyone would agree on precisely how and why the migrating pore fluids account for the phenomena attributed to them, it is clear that if dilatancy is applicable at all it must be applicable to seismic activity extending over at least tens of years (because the precursors of very large earthquakes appear several decades ahead of the main shock). But what part, if any, does fluid flow play in aftershock sequences which also occur within this time scale? The question was first investigated by Nur and Booker (Science, 175, 885; 1972) some years ago. But in having another look at it, Robinson et al. (Geophys. J., 41, $37 ; 1975$ ) have made an unexpected and encouraging discovery-encouraging because it shows that dilatancy concepts may be adapted successfully to explain phenomena at least one step removed from those for which they were originally conceived.

The particular sequence studied by Robinson and his colleagues was that of the Inangahua, New Zcaland, earthquake of 1968 (magnitude 7.1). The general properties of aftershock sequences, however, are already well known. Thus the frequency of aftershocks immediately after a large shallow earthquake is typically thousands a day and decays with time to perhaps ten or fewer shocks a day 100 days later. Up to a year at least, the frequency is approximately inversely proportional to time and is related to magnitude (of the aftershocks themselves) through the well known GutenbergRichter equation in which log (frequency) is proportional to magnitude with a constant of proportionality $b$ (the so-called $b$ value). Geographically, aftershocks are closely related to the fault region of the main shock, and most of them have focal mechanisms similar to that of the main shock.

When Adams and Lowry (New Zealand R. Soc. Bull., 9, 129; 1971) investigated the Inangahua aftershocks a few years ago, they found them to be no exception to these general rules. The $b$ value was roughly unity, the shock frequency varied as (time $)^{-1.05}$, the epicentres lay within an elliptical area about $45 \mathrm{~km} \times 25 \mathrm{~km}$ extending SSW from near the main shock's epicentre, and both the main shock and most of the aftershocks were apparently due to thrust faulting. But Adams and Lowry only looked at the first 40 days of the sequence. Robinson et al., by contrast, returned to study the sequence 3.6 years after it had begun, by which time the magnitude level had decreased to that of microearthquakes. What they found was that the $b$ value was still about 1 (having remained constant for more than $3 \frac{1}{2}$ years and over a magnitude range of 5), that the shock frequency had continued to decrease with time in the same way (actually as (time $)^{-1.06}$ ) and that the new epicentres were distributed as the old (the clliptical area had contracted marginally). But the faulting had changed completely, from the dominant thrust movement of the main shock and early aftershocks to the main normal movement of the later aftershocks.

On the face of it, this is surprising. The regional tectonic stress is compressive and thus hardly conducive to normal faulting unless both the stress is reduced to a low level and material is removed at depth. The earthquake and its aftershocks themselves will reduce the stress, but what could remove the material? The obvious explanation, of course, is that the pore fluids which entered the source region before the earthquake have now flowed out again. In general terms, the 